DOI: https://doi.org/10.24127/ajpm.v9i1.2632

\title{
KEMAMPUAN PEMECAHAN MASALAH MATEMATIS MATERI EKSPONEN DAN LOGARITMA DITINJAU DARI GAYA BELAJAR DAN PERBEDAAN GENDER
}

\author{
Dian Purwaningsih ${ }^{1)}$, Anwar Ardani ${ }^{2)}$ \\ ${ }^{1,2}$ Pendidikan Matematika, Universitas Peradaban, Brebes, Indonesia \\ E-mail: $\quad$ dedepurwa24@gmail.com ${ }^{1)}$ \\ $\underline{\text { anwarardani3@gmail.com }}^{2)}$
}

Received 18 January 2020; Received in revised form 02 February 2020; Accepted 28 March 2020

\begin{abstract}
Abstrak
Penelitian ini bertujuan mendeskripsikan kemampuan pemecahan masalah matematis materi eksponen dan logaritma siswa kelas X ditinjau dari gaya belajar dan perbedaan gender. Jenis Penelitian yang digunakan dalam penelitin ini adalah penelitian kualitatif. Penelitian ini dilaksanakan di SMK Al Huda Bumiayu Tahun 2019/2020. Subyek penelitian ini adalah Siswa Kelas X TKJ 2 SMK AL Huda Bumaiyu. Instrument pengumpulan data yang digunakan yaitu observasi, angket, wawancara dan tes. Hasil tes kemampuan pemecahan masalah diperoleh VP tidak dapat melaksanakan rencana dan tidak dapat memeriksa kembali proses dan hasil. Sedangkan VL tidak dapat memahami masalah dan merencanakan penyelesaian, serta tidak dapat memeriksa kembali proses dan hasil, namun VP mempunyai ciri-ciri rapi dan teratur dibandingkan dengan VL. AP dan AL tidak dapat melaksanakan rencana dengan baik, keduanya mempunyai ciri-ciri merasa kesulitan untuk menulis tetapi hebat dalam bercerita. KP dan KL tidak dapat memahami masalah, merencanakan penyelesaian, melaksanakan rencana dengan baik dan tidak dapat memeriksa kembali proses dan hasil, keduanya mempunyai ciri-ciri tidak mudah mengingat dan berbicara dengan perlahan. Kesimpulan dalam penelitian ini yaitu bahwa setiap siswa dapat menyelesaikan permasalah pada suatu persoalan matematika dengan kemampuan yang dimilikinya, dikarenakan siswa tersebut memiliki karakteristik gaya belajar yang berbeda-beda.
\end{abstract}

Kata kunci: Eksponen; gaya belajar; gender; logaritma; pemecahan masalah matematis.

\begin{abstract}
This study aims to describe the mathematical problem solving ability of exponents and logarithms of class $X$ students in terms of learning styles and gender differences. This type of research used in this research is qualitative research. This research was conducted at Al Huda Bumiayu Vocational School in 2019/2020. The subjects of this study were Class X TKJ 2 Students of SMK AL Huda Bumaiyu. Data collection instruments used were observation, questionnaire, interview and test. The results of the problem-solving ability test were obtained by VP unable to carry out the plan and unable to re-examine the process and results. While VL cannot understand problems and plan solutions, and cannot re-examine processes and results, VP has neat and orderly characteristics compared to VL. AP and AL cannot carry out the plan properly, both have the characteristics of having difficulty writing but are great at storytelling. KP and KL cannot understand the problem, plan the solution, carry out the plan properly and cannot re-examine the process and the results, both of which have characteristics that are not easy to remember and speak slowly. The conclusion in this study is that each student can solve problems on a mathematical problem with the ability he has, because these students have different learning style characteristics.
\end{abstract}

Keywords: Exponents; learning style; gender; logarithms; mathematical problem solving.

\section{PENDAHULUAN}

Aktivitas dalam pembelajaran matematika di sekolah salah satunya melalui pemecahan masalah. Menurut
Fadillah (2009) bahwa pemecahan masalah matematis adalah suatu aktivitas kognitif yang kompleks, sebagai proses untuk mengatasi suatu 
masalah yang ditemui dan untuk menyelesaikannya diperlukan sejumlah strategi. Pemecahan masalah bertujuan untuk melihat pemahaman siswa terhadap suatu materi. Selaras dengan yang diungkapkan Nur \& Palobo (2018) bahwa pemecahan masalah merupakan sarana siswa memahami, merencanakan, memecahkan dan meninjau kembali solusi yang diperolehnya melalui strategi yang bersifat non rutin.

Pemecahan masalah membutuhkan sebuah proses dalam menyelesaikanya. Menurut Nur \& Palobo (2018) menyatakan bahwa proses pemecahan masalah merupakan proses kompleks yang memerlukan pikiran secara fleksibel dan dinamis. Sedangkan menurut Utami \& Wutsqa (2017) berpendapat bahwa kemampuan pemecahan masalah erat kaitannya dengan keyakinan siswa dalam menyelesaikan soal, karena keyakinan yang dimiliki siswa dalam pemecahan masalah akan mempengaruhi hasil belajar siswa. Berdasarkan hal tersebut, maka pemecahan masalah sangat penting dalam pembelajaran. Salah satu faktor yang mempengaruhi perbedaan kemampuan pemecahan masalah adalah gaya belajar. .

(2014) berpendapat bahwa cara seseorang menyerap informasi, mengolahnya, dan memanifestasikan dalam wujud nyata perilaku hidupnya disebut dengan gaya/tipe belajar. Gaya belajar yang tepat memberikan peran bagi siswa dalam memperoleh informasi yang diterima. Gaya belajar setiap siswa berbeda-beda, apalagi siswa yang terdiri dari bermacammacam karakteristik serta gender, maka dari itu guru harus dapat mengetahui gaya belajar siswa agar siswa dapat optimal dalam memahami dan menyerap informasi yang diterimanya. Menurut Nugraha \& Pujiastuti (2019) menyatakan bahwa perbedaan jenis kelamin siswa (gender) dapat mengakibatkan perbedaan psikologi belajar siswa. Perbedaan gender bukan hanya berakibat pada kemampuan dalam matematika tetapi memperoleh pengetahuan matematika itu sendiri (Aliyah, Yuhana, \& Santosa, 2019).

Penelitian yang sudah dilakukan oleh Akhyar \& Rokhmah (2018) menghasilkan bahwa terdapat pengaruh aktivitas belajar siswa terhadap kemampuan pemecahan masalah matematis siwa. Sedangkan yang dilakukan Riastini \& Mustika (2017) bahwa terdapat perbedaan kemampuan pemecahan masalah matematika antara kelompok siswa yang mengikuti pembelajaran menggunakan model Polya dan kelompok siswa yang mengikuti pembelajaran tidak menggunakan model Polya. Begitupula Zahriah, Hasan, \& Jalil (2016) menujukkan bahwa terjadi peningkatan signifikan kemampuan analisis dan hasil belajar siswa yang belajar dengan penerapan pemecahan masalah model Polya. Soenarjadi (2014) menghasilkan bahwa profil pemecahan masalah geometri antara subjek visual laki-laki dan subjek visual perempuan tidak menunjukkan perbedaan yang signifikan. Subjek auditory laki-laki lebih unggul dalam melakukan visual spasial dan subyek auditoy perempuan lebih teliti, lebih cermat dan lebih seksama. Subjek kinestetik laki-laki dan subjek kinestetik perempuan menunjukkan perbedaan yaitu subjek kinestetik laki-laki lebih unggul dalam melakukan visual spasial dan subjek kinestetik perempuan lebih teliti, lebih cermat dan lebih seksama. Adapula penelitian Umrana, Cahyono, \& Sudia 
(2019) bahwa kemampuan pemecahan masalah baik subyek visual, subyek auditorial, dan subyek kinestetik memiliki kemampuan yang berbedabeda.

Beberapa penelitian diatas, belum terdapat penelitian tentang kemampuan pemecahan masalah dinjau dari gaya belajar dan perbedaan gender dengan materi eksponen dan logaritma, sehingga hal ini memotivasi peneliti untuk melakukan penelitian yang diharapkan dapat meningkatkan kemampuan pemecahan masalah matematis siswa. Kebaruan penelitian ini yaitu pada materi eksponen dan logaritma.

Hasil observasi dan wawancara di kelas X TKJ 2 SMK Al Huda, siswa mempunyai kemampuan pemecahan masalah yang rendah karena siswa kurang siap dalam menghadapi persoalan-persoalan matematika disebabkan kurangnya kemauan siswa dalam belajar. Siswa yang mempunyai kemauan atau minat belajar tinggi, biasanya dapat menyelesaikan persoalan matematika dengan baik. Seperti yang diungkapkan Iriani \& Leni (2013) bahwa prestasi belajar yang baik dapat mencerminkan gaya belajar yang baik karena dengan mengetahui dan memahami gaya belajar yang terbaik bagi dirinya akan membantu siswa dalam belajar sehingga prestasi yang dihasilkan akan maksimal. Salah satu karakteristik siswa yang berpengaruh terhadap hasil belajar adalah gaya belajar (Chania, Haviz, \& Sasmita, 2016). Menurut DePorter \& Hernacki (2012) mengungkapkan gaya belajar seseorang adalah kombinasi dari bagaimana ia menyerap, dan kemudian mengatur serta mengolah informasi. Siswa dapat mengenali gaya belajarnya agar dapat belajar dengan tepat dan cepat, sehingga memperoleh hasil belajar yang baik.

Berdasarkan uraian latar belakang tersebut, maka penelitian ini bertujuan mendeskripsikan kemampuan pemecahan masalah matematis materi eksponen dan logaritma siswa kelas $\mathrm{X}$ ditinjau dari gaya belajar dan perbedaan gender.

\section{METODE PENELITIAN}

Jenis Penelitian yang digunakan dalam penelitin ini adalah penelitian kualitatif. Penelitian ini dilaksanakan di SMK Al Huda Bumiayu 2019/2020. Subyek penelitian ini adalah siswa kelas $X$ TKJ 2 SMK AL Huda Bumaiyu dengan jumlah 39 siswa. Metode pengumpulan data penelitian yaitu a) metode observasi, yaitu mengumpulkan data dengan pengamatan langsung kepada subyek penelitian; b) metode angket, dilakukan untuk mengetahui gaya belajar siswa dan gender sesuai dengan gaya belajar; c) metode wawancara, digunakan untuk mengetahui kemampuan pemecahan masalah matematika; d) metode tes, dilakukan secara tertulis kepada subyek penelitian sesuai dengan indikator kemampuan pemecahan masalah matematika menurut Polya (Purwaningsih \& Ardani, 2019). Instrument pengumpulan data yang digunakan yaitu observasi, angket, wawancara dan tes. Keabsahan data dalam penelitian ini mengunakan triangulasi.

Teknik analisis data yang dilakukan dalam penelitian yaitu analisis data yang melalui proses data reduction (reduksi data), data display (penyajian data), dan Conclusions drawing/verification (penarikan kesimpulan). Angket yang digunakan dirancang dengan menggunakan skala 
Likert untuk mengumpulkan data tentang gaya belajar dan gender dari masing-masing gaya belajar.

Tes kemampuan pemecahan masalah dianalisis untuk menentukan nilai dan kategori kemampuan pemecahan masalah. Kategori kemampuan pemecahan masalah berdasarkan modifikasi Ariani, Hartono, \& Hiltrimartin (2017) pada Tabel 1.

Tabel 1. Kategori kemampuan pemecahan masalah.

\begin{tabular}{ll}
\hline \multicolumn{1}{c}{ Nilai } & \multicolumn{1}{c}{ Kategori } \\
\hline $81 \leq x<100$ & Sangat baik \\
$61 \leq x<80$ & Baik \\
$41 \leq x<60$ & Cukup \\
$21 \leq x<40$ & Kurang \\
$0 \leq x<20$ & Sangat Kurang \\
\hline
\end{tabular}

\section{HASIL DAN PEMBAHASAN}

Penelitian yang dilakukan sebanyak tiga tahap dalam pengambilan data. Tahap yang pertama berupa angket gaya belajar, tahap kedua berupa tes kemampuan pemecahan masalah, tahap ketiga berupa wawancara. Angket gaya belajar digunakan untuk membagi gaya belajar menjadi tiga,yaitu gaya belajar visual, auditorial, kinestetik. Hal ini digunakan untuk mengumpulkan data dan pemilihan subyek. Hasil angket gaya belajar ada pada Tabel 2 .

Tabel 2. Hasil gaya belajar.

\begin{tabular}{ll}
\hline Gaya Belajar & $\begin{array}{l}\text { Jumlah } \\
\text { siswa }\end{array}$ \\
\hline Visual & 16 \\
Auditorial & 13 \\
Kinestetik & 10 \\
Total & 39 \\
\hline
\end{tabular}

Berdasarkan hasil angket gaya belajar siswa yang terdiri dari 39 siswa, yaitu gaya belajar visual ada 16 siswa, gaya belajar auditorial ada 13 siswa, dan gaya belajar kinestetik ada 10 siswa. Siswa yang dibagi menjadi tiga klasifikasi gaya belajar, kemudian dilanjutkan pada tahapan kedua yaitu tahap tes kemampuan pemecahan masalah. Hasil tes kemampuan pemecahan masalah dapat dilihat pada Tabel 3.

Tabel 3. Hasil tes kemampuan pemecahan masalah.

\begin{tabular}{|c|c|c|c|c|c|c|}
\hline \multirow[t]{3}{*}{ Kategori } & \multicolumn{6}{|c|}{ Gaya Belajar } \\
\hline & \multicolumn{2}{|c|}{ Visual } & \multicolumn{2}{|c|}{ Auditorial } & \multicolumn{2}{|c|}{ Kinestetik } \\
\hline & $\mathbf{P}$ & $\mathbf{L}$ & $\mathbf{P}$ & $\mathbf{L}$ & $\mathbf{P}$ & $\mathbf{L}$ \\
\hline Sangat Baik & - & - & - & - & - & - \\
\hline Baik & 2 & 1 & - & - & - & - \\
\hline Cukup & - & & 1 & 1 & - & 1 \\
\hline Kurang & 2 & 4 & 1 & 1 & 1 & 1 \\
\hline Sangat kurang & 5 & 2 & 7 & 2 & 6 & 1 \\
\hline
\end{tabular}

Tabel 3 menunjukkan bahwa hasil tes yang dilakukan sesuai tahapan Polya yang terdiri dari 4 langkah yaitu memahami masalah, merencanakan pemecahan masalah, melaksanakan pemecahan masalah, dan memeriksa kembali hasil. Tes ini bertujuan untuk memperoleh kemampuan pemecahan masalah baik laik-laki maupun perempuan yang sesuai dengan masingmasing gaya belajar.

Hasil tes kemampuan pemecahan masalah, dimana pemilihan subyek dilakukan secara acak dari tiga klasifikasi gaya belajar diperoleh hasil pada Gambar 1-6. 
DOI: https://doi.org/10.24127/ajpm.v9i1.2632

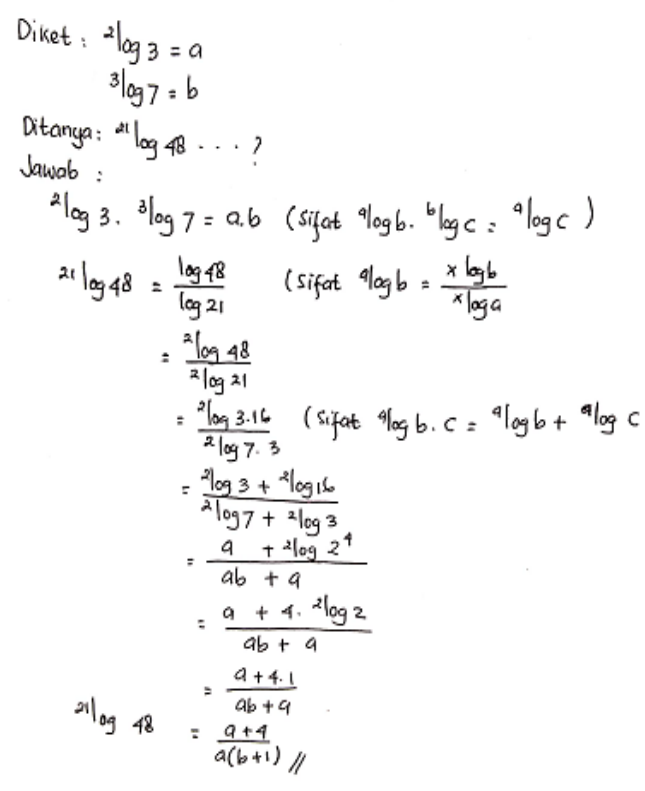

Gambar 1. Jawaban visual perempuan (VP).

$$
\begin{aligned}
& { }^{3} \log 7=b \Rightarrow{ }^{3} \log 7=\frac{\log 7}{\log 3} \\
& b=\frac{\log 7}{\log 3} \\
& \log 7=6 \cdot \log 3 \\
& { }^{2} \log 3=a \Longrightarrow 2 \log 3=\frac{\log 3}{\log 2} \\
& a=\frac{\log 3}{\log 2} \\
& \log z=\frac{\log 3}{a} \\
& 21 \log 48=\frac{\log 48}{\log 21} \\
& =\frac{\log \left(3 \cdot 2^{4}\right)}{\log (3 \cdot 7)} \\
& =\frac{\log 3+\log 24}{\log 3+\log 7} \\
& =\frac{\log 3+4 \log 2}{\log 3+\log 7} \\
& =\frac{\log 3+4 \frac{\log 3}{a}}{\log 3+b \cdot \log 3} \times \frac{a}{a} \\
& =\frac{a \cdot \log 3+4 \log 3}{a \log 3+a b \log 3} \\
& =\frac{a+4}{a+a b}
\end{aligned}
$$

Gambar 2. Jawaban visual laki-laki

(VL).

Berdasarkan Gambar 1 dan 2 terlihat VP dapat menyelesaikan dengan sistematis yaitu pada bagian diketahui, ditanyakan, menguraikan jawaban dengan lengkap menurut sifat-sifat logaritma, namun tidak dapat memberikan kesimpulan. Sedangkan
VL dapat menyelesaikan jawaban dengan baik, namun VL tidak menyelesaikan secara sistematis.

$$
\begin{aligned}
& \text { Diket }=2 \log 3=a \\
& { }^{3} \log 7=b \\
& \text { Dit }=21 \log 48 \ldots \text { ? } \\
& \text { Jw6: }{ }_{21} \log 48=\frac{\log 48}{\log 21} \\
& { }^{2} \log 3=a \\
& 3 \log 7=b \\
& { }^{2} \log 3 \cdot{ }^{3} \log 7={ }^{2} \log 7=a \cdot b \\
& { }^{21} \log 48=\frac{\log 48}{\log 21} \\
& =\frac{\log (3.16)}{\log (3.7)}
\end{aligned}
$$

Gambar 3. Jawaban auditorial perempuan (AP).

$$
\begin{aligned}
& \text { Diket: }{ }^{2} \log 3=a \quad 2 \log 3,{ }^{3} \log 7=a \cdot b \\
& { }^{3} \log 7=b \\
& \text { Dit : }{ }^{21} \log 48 \\
& \text { Jwb: } \quad 21 \log 48=\frac{\log 48}{\log 21} \\
& =\frac{\log (3.16)}{\log (3.7)} \\
& =\frac{{ }^{2} \log 3+{ }^{2} \log 16}{2 \log 3+{ }^{2} \log 7} \\
& =\frac{a+{ }^{2} \log 16}{a+{ }^{2} \log 7}
\end{aligned}
$$

Gambar 4. Jawaban auditorial laki-laki (AL).

Berdasarkan Gambar 3 dan 4, terlihat AP dan AL tidak dapat menyelesaikan jawaban dengan baik pada tahap melaksanakan rencana, yaitu saat menguraikan jawaban sampai selesai dengan baik. 


$$
\begin{aligned}
& \text { Diket }={ }^{2} \log 3=a \\
& 3 \log 7=b \\
& \text { Dit }=21 \log 48 \cdots ? \\
& \text { Jub }=21 \log 48=\frac{\log 48}{\log 21} \\
&=\frac{\log (3.16)}{\log (3.7)} \\
&=\frac{\log 3+\log 16}{\log 3+\log 7} \\
&=\frac{\log 3+\log 2}{\log 3+\log 7}
\end{aligned}
$$

Gambar 5. Jawaban kinestetik perempuan (KP).

$$
\begin{aligned}
\text { Diket }= & 2 \log 3=a \\
& 3 \log 7=b \\
\text { Dit }= & 21 \log 48 \ldots ? \\
J \operatorname{lob}= & =\frac{\log 48}{\log 21} \\
2 \log 3= & \frac{\log (3 \cdot 16)}{\log (3 \cdot 7)} \\
2 \log 40 & =\frac{\log 3+\log 16}{\log 3+\log 7} \\
& =\frac{1+\log 16}{1+\log 1}
\end{aligned}
$$

Gambar 6. Jawaban Kinestetik LakiLaki (KL)

Berdasarkan Gambar 6 dan 7 terlihat KP dan KL tidak dapat menyelesaikan jawaban dengan sistematis yaitu pada bagain diketahui dan ditanyakan, kemudian KP dan KL tidak dapat menyelesaikan jawaban pada saat menguraikan jawaban.

Tahap ketiga yaitu tes wawancara. Wawancara yang dilakukan bertujuan mengkonfirmasi dan meng- klarifikasi jawaban subyek. Wawancara yang dilakukan yaitu wawancara yang tak berstruktur atau terbuka, hal ini dilakukan untuk mengetahui dan mengembangkan jawaban subyek yang lebih mendalam. Hasil wawancara terhadap VP dan VL diperoleh jawaban bahwa siswa tersebut mengalami masalah menyampaikan jawaban dengan secara rinci dikarena-kan siswa mempunyai masalah untuk mengingat instruksi secara verbal sehingga jawaban lebih singkat, namun siswa merasa mudah dalam menjawab secara tertulis. Hasil wawancara AP dan AL bahwa siswa dapat memahami apa yang ditanyakan dalam soal, namun siswa tidak dapat menyelesaikan jawaban sampai akhir. AP dan AL dapat menjelaskan jawaban dengan lancar ketika ditanya secara lisan. Hasil wawancara KP dan KL diperoleh bahwa siswa tersebut dapat menjelaskan jawaban dengan terbata-bata dan siswa merasa kurang mampu menyelesaikan jawaban dengan baik secara tertulis.

Berdasarkan hasil tes kemampuan pemecahan masalah dan wawancara tersebut diatas, maka dapat disimpulkan bahwa VP tidak dapat melaksanakan rencana dan tidak dapat memeriksa kembali proses dan hasil. Sedangkan VL tidak dapat memahami masalah dan merencanakan penyelesaian, serta tidak dapat memeriksa kembali proses dan hasil, namun VP mempunyai ciri-ciri rapi dan teratur dibandingkan dengan VL. AP dan AL tidak dapat melaksanakan rencana dengan baik, keduanya mempunyai ciri-ciri merasa kesulitan untuk menulis tetapi hebat dalam bercerita. KP dan KL tidak dapat memahami masalah, merencanakan penyelesaian, melaksanakan rencana dengan baik dan tidak dapat memeriksa kembali proses dan hasil, keduanya mempunyai ciri-ciri tidak mudah 
mengingat dan berbicara dengan perlahan.

Setiap siswa, baik laki-laki
maupun perempuan memiliki
karakteristik gaya belajar masingmasing, sehingga akan mempengaruhi kemampuan siswa dalam berpikir menyelesaikan suatu masalah matematika materi eksponen dan logaritma. Hal ini sejalan dengan penelitian Umrana, Cahyono, \& Sudia (2019) bahwa kemampuan pemecahan masalah baik subyek visual, subyek auditorial, dan subyek kinestetik memiliki kemampuan yang berbedabeda. Berbeda dengan hasil penelitian Soenarjadi (2014) menghasilkan bahwa subjek visual laki-laki dan subjek visual perempuan tidak menunjukkan perbedaan yang signifikan. Subjek auditory laki-laki lebih unggul dalam melakukan visual spasial dan subyek auditoy perempuan lebih teliti, lebih cermat dan lebih seksama. Subjek kinestetik laki-laki dan subjek kinestetik perempuan menunjukkan perbedaan yaitu subjek kinestetik laki-laki lebih unggul dalam melakukan visual spasial dan subjek kinestetik perempuan lebih teliti, lebih cermat dan lebih seksama.

Berdasarkan pembahasan di atas pemecahan model Polya dapat digunakan sebagai salahsatu indikator dalam penyelesaian masalah matematis. Kemampuan pemecahan masalah merupakan masalah yang mendasar dalam pembelajaran matematika, maka sebaiknya kemampuan pemecahan masalah diajarkan pada siswa sejak awal agar hasil yang diharapkan dapat tercapai dan memberikan kesempatan pada siswa untuk belajar sesuai gaya belajar masing-masing siswa.

\section{KESIMPULAN DAN SARAN}

Kesimpulan dalam penelitian ini yaitu bahwa setiap siswa dapat menyelesaikan permasalah pada suatu persoalan matematika dengan kemampuan yang dimilikinya, dikarenakan siswa tersebut memiliki karakteristik gaya belajar yang berbeda-beda. Subyek yang memiliki perbedaan yang signifikan yaitu pada subyek gaya belajar visual perempuan cukup baik dalam menyelesaikan masalah matematika dibandingkan dengan subyek laki-laki. Sedangkan subyek dengan gaya belajar auditorial dan kinestetik tidak memiliki perbedaan yang signifikan, baik subyek laki-laki maupun perempuan.

Saran bagi siswa yaitu siswa diharapkan dapat menemukan gaya belajar yang sesuai agar dapat mencapai hasil belajar yang maksimal. Bagi guru, sebaiknya mengkondisikan penggunaan strategi pembelajaran. Bagi peneliti, sebaiknya memberikan tes pemecahan masalah yang bervariasi.

\section{DAFTAR PUSTAKA}

Akhyar, M. K., \& Rokhmah, M. (2018). Efektivitas Model Pembelajaran Knisley Berbasis Masalah Terhadap Kemampuan Pemecahan Masalah Matematis pada Pokok Bahasan PLDV. JES-MAT Vol. 4, No. 2, 141-152.

Aliyah, I. M., Yuhana, Y., \& Santosa, C. A. (2019). Kemampuan Koneksi Matematis Siswa Ditinjau dari Kemampuan Awal dan Gender. Jurnal Dikdaktik Matematika Vol. 6, No. 2, 161-178.

Ariani, S., Hartono, Y., \& Hiltrimartin, C. (2017). Kemampuan Pemecahan Masalah Matematika Siswa pada Pembelajaran Matematika Menggunakan Strategi AbduktifDeduktif di SMA Negeri 1 
DOI: https://doi.org/10.24127/ajpm.v9i1.2632

Inrdalaya Utara. Jurnal Elemen, Vol. 3 No. 1, 25-34.

Bire, A. L., Geradus, U., \& Bire, J. (2014). Pengaruh Gaya Belajar Visual, Auditorial, dan Kinestetik Terhadap Prestasi Belajar Siswa. JURNAL KEPENDIDIKAN, Vol. 44, No. 2, 168-174.

Chania, Y., Haviz, M., \& Sasmita, D. (2016). Hubungan Gaya Belajar Dengan Hasil Belajar Pada Pembelajaran Biologi Kelas X SMA 2 Sungai Tarab Kabupaten Tanah Datar. Journal of Sainstek Vo. 8, No. 1, 77-84.

DePorter, B., \& Hernacki, M. (2012). Quantum Learning "Membiasakan Belajar Nyaman dan Menyenangkan". Bandung: Kaifa.

Fadillah, S. (2009). Kemampuan Pemecahan Masalah Matematis Dalam Pembelajaran Matematika. Seminar Nasional Penelitian, Pendidikan dan Penerapan MIPA (pp. 553-558). Yogyakarta: Fakultas MIPA Universitas Negeri Yogyakarta.

Iriani, D., \& Leni, M. (2013). Identifikasi Gaya Belajar dan Pengaruhnya terhadap Hasil belajar Siswa pada Materi Kubus dan Balok di Kelas VII SMPN 2 Kerinci. Semirata FMIPA (pp. 109-114). Lampung: Universitas Lampung.

Nugraha, T. H., \& Pujiastuti, H. (2019). Analisis Kemampuan Komunikasi Matematis Siswa Berdasarkan Perbedaan Gender. Edumatica Vol. 09, No. 01, 1-7.

Nur, A. S., \& Palobo, M. (2018). Profil Kemampuan Pemecahan Masalah Matematika Siswa Ditinjau Dari Perbedaan Gaya Kognitif dan Gender. Jurnal Matematika Kreatif-Inovatif Vol. 9, No.2, 139148.
Purwaningsih, D., \& Ardani, A. (2019). Analisis Kemampuan Pemecahan Masalah Matematika Menurut Polya pada Materi Transformasi Linier. Jurnal Penidikan Surya Edukasi Vol.5, No.1, 69-76.

Riastini, P. N., \& Mustika, I. A. (2017). Pengaruh Model Polya Terhadap Kemampuan Pemecahan Masalah Matematika Siswa Kelas V SD. International Journal of Elementary Education Vol.1, No. 3, 189-196.

Soenarjadi, G. (2014). Profil Pemecahan Masalah Geometri Siswa MTs Ditinjau dari Perbedaan Gaya Belajar dan Perbedaan Gender. Jurnal Widyaloka IKIP Widyadarma Surabaya Vol. 1, No.2, 162-175.

Umrana, Cahyono, E., \& Sudia, M. (2019). Analisis Kemampuan Pemecahan Masalah Matematis Ditinjau dari Gaya Belajar SIswa. Jurnal Pembelajaran Berpikir Matematika Vol. 4 No. 1, 67-76.

Utami, R. W., \& Wutsqa, D. U. (2017). Analisis Kemampuan Pemecahan Masalah Matematika dan SelfEfficacy Siswa SMP Negeri di Kabupaten Ciamis. Jurnal Riset Pendidikan Matematika Vol. 4, No. 2, 166-175.

Zahriah, H., M., \& Jalil, Z. (2016). Penerapan Pemecahan Masalah Model Polya untuk Meningkatkan Kemampuan Analisis dan Hasil Belajar pada Materi Vektor di SMA 1 Darul Imarah. Jurnal Pendidikan Sains Indonesia, 4(2), 151-161. 